\title{
ABHANDLUNGEN
}

DER PREUSSISCHEN

\section{AKADEMIE DER WISSENSCHAFTEN}

\author{
JAHRGANG 1919
}

PHILOSOPHISCH-HISTORISCHE KLASSE

NR. 10

VOM KLOSTERBUCH DES ŠÂBUŠTÎ

VON

EDUARD SACHAU

BERLIN 1919

VERLAG DER AKADEMIE DER WISSENSCHAFTEN

IN KOMIMISSION BEI DER

VEREINIGUNG WISSENSCHAFTLICHER VERLEGER WALTER DE GRUYTER U. CO.

VORMALS 6. J. GOSCHEN SCHE VERLAGSHANDLUNG, J. GUTTENTAG, VERLAOSBUCHHANDLLNG.

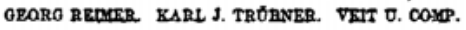


Vorgelegt in der Sitzung der phil.-hist. Klasse am 22. Mai 1919.

Zum Druck eingereicht am 6. Juni, ausgegeben am 29. September 1919. 